\title{
Mercury concentrations in Pacific Ocean tunas are driven by both anthropogenic and natural factors
}

\author{
ANAÏS MÉDIEU ${ }^{1}$, DAVID POINT ${ }^{2}$, TAKAAKI ITAI ${ }^{3}$, \\ HÉLÈNE ANGOT ${ }^{4}$, PEARSE BUCHANAN ${ }^{5}$, VALÉRIE \\ ALLAIN $^{6}$, SHANE GRIFFITHS ${ }^{7}$, LEANNE FULLER ${ }^{7}$, \\ DAVID GILLIKIN $^{8}$, JEROEN E SONKE ${ }^{9}$, LARS-ERIC \\ HEIMBUERGER-BOAVIDA ${ }^{10}$, CHRISTOPHE E. MENKES ${ }^{11}$, \\ DANIEL MADIGAN $^{12}$, ALESSANDRO TAGLIABUE ${ }^{5}$, \\ LAURENT BOPP ${ }^{13}$, ANOUK VERHEYDEN ${ }^{14}$ AND ANNE \\ LORRAIN $^{11}$ \\ ${ }^{1}$ Université Bretagne Occidentale \\ ${ }^{2}$ Géosciences Environnement Toulouse, CNRS/IRD/Université \\ Paul Sabatier Toulouse III \\ ${ }^{3}$ The University of Tokyo \\ ${ }^{4}$ University of Colorado Boulder \\ ${ }^{5}$ University of Liverpool \\ ${ }^{6}$ Pacific Community \\ ${ }^{7}$ Inter-American Tropical Tuna Commission \\ ${ }^{8}$ Union College (US) \\ ${ }^{9} \mathrm{CNRS} /$ Université de Toulouse \\ ${ }^{10}$ Institut Méditerranéen d'Océanologie - MIO, CNRS \\ ${ }^{11}$ IRD \\ ${ }^{12}$ University of Windsor \\ ${ }^{13} \mathrm{CNRS}$ \\ ${ }^{14}$ Union College \\ Presenting Author: anais.medieu@ird.fr
}

Tunas are one of the most consumed seafood products but are also the main conduit to human methylmercury exposure, a potent neurotoxin. Anthropogenic mercury emissions outweigh their natural counterpart by a factor 5, and yet, how anthropogenic mercury is converted into oceanic methylmercury and how this translates into tuna methylmercury concentrations is unclear. A model of mercury concentrations in skipjack tunas for the Pacific Ocean was built, combining ecological, environmental and mercury atmospheric data. We show that the footprint of mercury in skipjack is regionally driven, with hemispherical and zonal gradients. While maximum levels occur near Asia, associated with elevated anthropogenic emissions, high concentrations are also found in the eastern Pacific where high productivity and oxygen depleted waters stimulate methylation. The historical growth and projected expansion of oceanic oxygen minimum zones associated with global warming may therefore delay the efficiency of mitigation policies implemented under the Minamata convention. 